\title{
Measuring Conference Attendees' Satisfaction: An Insight from Libya
}

\author{
Ahmed Atia ( $\square$ ah.atia@uot.edu.ly) \\ University of Tripoli, Libya https://orcid.org/0000-0002-9951-1921 \\ Ahmed Abired \\ Tripoli Higher Institute for Medical Professions, Libya \\ Halla Elshwekh \\ Biotechnology Research Center, Libya \\ Nagib Elmarzugi \\ University of Tripoli, Libya https://orcid.org/0000-0001-7108-8028
}

\section{Research Article}

Keywords: Conference, Attendees, satisfaction, Libya

Posted Date: June 22nd, 2020

DOI: https://doi.org/10.21203/rs.3.rs-36465/v1

License: (c) (1) This work is licensed under a Creative Commons Attribution 4.0 International License. Read Full License 


\section{Abstract}

Background and objectives: Even with the widespread repetition of organizing events and conferences by hosting organizations, little is known about the influence of such meeting on attendee's satisfaction. However, up to our knowledge, there is no exploratory survey measured the satisfaction of conference attendees in Libya. Hence, this study sought to reveal the that impact of the effectiveness of conference messages on the attendee's satisfaction.

Methods: A self-report survey designed to assess satisfaction with conference attributes was completed by 78 attendees following their participation in the 3rd Libyan conference on medical and pharmaceutical sciences held in Libya. The questionnaires were circulated through personal contact with respondents at the conference.

Results: Based on data analysis, the lowest mean values ranging between "Poor satisfaction" and "fair" (from 2.8 to 3.4) have the attributes: networking, venue of the conference, and the new knowledge. Furthermore, the highest rating was assigned to the conference organization and quality of service, technical support, and conference program. Generally, it is obvious that the attendees are not completely satisfied with the conference in general and specifically with some conference attributes, which are related to the networking and the conference venue.

Conclusion: The results of this study suggest that the organizer should pay more attention to the venue selection process, as it affects overall quality of the conference. Further comparable studies, regarding conference satisfaction should be conducted in other conference venues and settings in Libya, in order to raise the quality of services destination attractiveness.

\section{Introduction}

The scientific conference, as a part of educational method, is globally recognized for its valuable scientific and economic input to tourism destination. Attending a conference in any field can broaden the attendee's network, promote deeper understanding, uncover new learnings and reinforce existing best practices [1].

The number of events per year in the International Conference and Congress Association (ACCA) database has grown by almost 12.951 events over the past 10 years [2]. As the number of conferences rises and attendees have several conferences to select from, consideration of how they estimate the conference experience is more significant than ever. Earlier reports have focused on site assortment aspects, destination insight, financial influence, and meeting organizer issues, not on the conference experience itself [3].

To conduct and track an event and a scientific forum, one of the most important things is to have an assessment of needs and expectations for attendees to create a scientific environment that includes science, work, marketing, strategic goals and arranging events. This will allow for evaluating the 
materials, lectures and workshops presented during the meeting related to the subject of this event [4]. It gives the attendees the opportunity to start an opinion on this event from various aspects, whether organizational, supervisory or service, such as the display platform, presentation or amplifiers, seminar topics, training sessions, the exhibition accompanying the meeting, exhibitors and sponsors, accommodation, scientific material [4].

Although paucity of studies has explored variables that impact conference satisfaction, the competition among conference destinations and locations has painted the necessity for the assessment of the conference attendees' satisfaction [5,6]. Previous study has revealed that the conference experience itself can ensure attendees' satisfaction by offering them a chance to keep them updated in their area of interest, to learn new skills, and to allow them to catch valued experts in their field [7]. Likewise, in another study, surveyed attendees were pleased with the informative profits and present a stronger satisfaction with the conference, and were more likely to tell others to join the conference [8].

In Libya, there is no study conducted to measure the satisfaction of conference attendees up to our knowledge so far. Therefore, this study is aimed to evaluate conference attendees' satisfaction during attending the third Libyan Conference on Medical and Pharmaceutical Sciences in Janzur, Libya.

\section{The third Libyan Conference on Medical and Pharmaceutical Sciences}

On Sep 28, 2019, the third Libyan Conference on Medical and Pharmaceutical Sciences (3rd LCMPS) brought together healthcare-expertise and trainees from several local institutions concerned in health promotion for full day of meetings, interactive panels, breakout gatherings and networking. The conference offers a leading forum for the presentation of new research results in the fields of Pharmacy and Medicine. The conference opened with three keynote speakers addressing the role of pharmaceutical care in health system followed by an interactive panel discussion with researchers on advocacy, activism, and their personal career activities. The $3^{\text {rd }}$ LCMPS serves to foster communication among researchers and practitioners working in a wide variety of scientific areas with a common interest in improving pharma sciences and medicine and related techniques.

\section{Methodology}

This was a cross-sectional questioner-based study conducted during the 3dr LCMPS day on September 2019. The questionnaire was divided into two parts. The first part contains four queries related to sociodemographic features about participants. The second part involves thirteen inquiries concerned to their perception toward the conference (seven conference attributes and six destination attributes). In the second part, the respondents stated opinions on the level of their satisfaction of mentioned elements of the conference using a five-point Likert scale, ranking from "very dissatisfied" (1) to "very satisfied" (5). The conference was held at the "University of Tripoli Alahlia" in Janzur on 28 Sept 2019. 
The conference agenda was separated into two parts: the first part was held a professional conference, meeting professors-lecturers at the conference, while the second part students-involvements at the conference. The sample involved expertise/student participants, and posters who contributed at the poster session at the conference. The questionnaires were circulated through personal contact with respondents at the conference. There were 116 distributed questionnaires, and 78 respondents have completed them properly. The data was analyzed using Statistical Packages for Social Sciences (SPSS).

\section{Results}

\section{Respondents Characteristics}

Of 116 surveyed participants, only 78 had completed the questioner properly with the response rate of $67.2 \%$.

Table 1 shows demographics of respondents, with the sample contained slightly more females (53.9\%) than males (46.1\%). Most of the respondents belong to the age group of $26-35$ years $(41 \%)$. This finding was not surprising because of the nature of the conference, whose participants were mostly graduate students. The lowest number of participants belongs to the age group of over 50 years ( $9 \%$ ). According to the state of origin, attendees were divided into 2 groups. The first group includes participants from the host country - Libya, the second group includes participants from outside the countries. The study was dominated with Libyans ( $94.8 \%$ ). By their education level, respondents holding a post-university degree are dominant making total of $73.1 \%$, followed by bachelor degree $(26.9 \%)$.

Table 1. Demographic profile characteristics of the respondents $(n=78)$ 


\begin{tabular}{|lll|}
\hline Characteristics & Frequencies & Percentages \\
\hline Gender & & \\
\hline Male & 36 & $46.1 \%$ \\
\hline Female & 42 & $53.9 \%$ \\
\hline Age group & & \\
\hline $18-25$ & 17 & $21.8 \%$ \\
\hline $26-35$ & 32 & $41 \%$ \\
\hline $36-50$ & 22 & $28.2 \%$ \\
\hline Over 50 & 7 & $9 \%$ \\
\hline State of origin & & \\
\hline Libyan & 74 & $94.8 \%$ \\
\hline Non-Libyan & 4 & $5.2 \%$ \\
\hline Education level & & \\
\hline Bachelor & 21 & $26.9 \%$ \\
\hline MSc/PhD & 57 & $73.1 \%$ \\
\hline
\end{tabular}

Due to the nature of the conference, which has primarily a scientific character, these results were expected. Since the junior academic staff started the organization of this conference, it is expected that attendees were mostly in the age of 26 to 35 years old. The largest number of participants were Libyans is also expected, primarily because of the country's security situations that will not be save for international participants to join the conference. Moreover, a large percentage of highly educated respondents is again associated with the scientific character of the conference, and all other events in the research activities which itself is referred to a highly educated staff.

\section{Results of descriptive statistical analysis}

Of all the analyzed conference attributes, the lowest mean values ranging between "Poor satisfaction" and "fair" (from 2.8 to 3.4) have the attributes: networking, venue of the conference, and the new knowledge. In an expectant manner, the highest rating was assigned to the conference organization and quality of service, technical support, and conference program (Fig. 1).

Figure 2 shows the mean values and standard deviation of attributes related to conference destination. Generally, the attributes related to conference destination are better rated than the conference attributes. As mean values of destination attributes are higher than 4.1, it could be concluded that the respondents 
are generally satisfied with destination choice for the conference and the host was perceived by the respondents as an attractive destination. Attributes such as hospitality of local residents, safety level and attractiveness were evaluated with relatively high grades. Transit position of Janzur city which consider among the safest places could contributes significantly to the good rates for safety and attractiveness.

\section{Discussion And Conclusion}

Janzur is recognized as a good destination in Libya for hosting international events such as congresses, conferences, exhibitions and similar events, as this city has necessary infrastructure for holding events such as palm city, Libyan academia for higher studies, and University of Tripoli Alahlia. To continue this tendency in the future and to provide quality conference product, it is important for destination management organizations, hotels, congress centers and other venues hosting conferences, to conduct studies with the aim to examine conference attendees' satisfaction and behavioral intentions.

The research interpreted in this paper about the conference attendees' satisfaction was conducted at University of Tripoli Alahlia, consisting of conference attendees, who voluntary took part in the research. Based on the results obtained in analysis of the attendees' satisfaction with the conference related attributes, it is obvious that the attendees are not completely satisfied with the conference in general and specifically with some conference attributes, which are related to the networking and the conference venue. Therefore, it can be concluded that the organizer should pay more attention to the venue selection process, as it affects overall quality of the conference. The conference program, quality of service as well as the organization and technical support are rated as satisfactory. However, it was surprising that gaining new knowledge were assigned as "fair".

Several earlier reports reveled that networking, acquisition of new knowledge and conference agenda are significant aspect that impact conference attendance. Nevertheless, this questionnaire-based report takes these characteristics one step further by examining satisfaction with the same features adding destination related attributes. This work tries to highlight the reputation of destination related attributes for the total conference attendees' satisfaction. Hence, the outcomes are valuable for conference venue owners, and particularly, to conference organizers $[9,10]$.

Further comparable studies, regarding satisfaction, experience, social intentions and conference attendee's loyalty, and conference organizers, should be conducted in other conference venues and settings in Libya, in order to raise the quality of services, destination attractiveness and successfully encourage Libya as an attractive conference destination.

\section{Declarations}

\section{ACKNOWLEDGMENT}

We acknowledge the conference committees and host organizers for their support. 
A statement on participant consent - All included participants were agreed to participate in this study and signed the consent form. The study was approved by the research ethical committee and conference organizers.

Competing interests: The authors declare no competing interests.

\section{References}

1. Weber, K. and Chon, K. 2002. Convention tourism international research and industry perspectives, Haworth Press Inc.,U.S.

2. ICCA Statistics Report 2018, International Association Meetings Market. Available from:file:///C:/Users/user/Desktop/2018-Country-and-City-Rankings_PublicAbstract.pdf. [Last accessed April 1, 2020].

3. DeFranzo S. The Importance of Post-Event Surveys. Snap surveys. Available from: https://www.snapsurveys.com/blog/importance-postevent-surveys/. [Last accessed April 1, 2020].

4. Bauer, T., Law, R., Tse, T. And Weber, K. (2008). Motivation and satisfaction of mega business event attendees: The case of ITU telecom world 2006 in Hong Kong. Intern. J. Cont. Hosp. Manag. 2008;20(2):228-234.

5. Kim S, Lee Y. Love C. A case study examining the influence of conference food functions on attendee satisfaction and return intention at a corporate conference. Journal of Convention \& Event Tourism. 2009;10 (3):211-230.

6. Tanford S, Montgomery R, Nelson K. Factors that Influence Attendance, Satisfaction, and Loyalty for Conventions. Journal of Convention \& Event Tourism. 2012;13(4):290-318.

7. Zhanga Q, Leunga V, Qu H. A refined model of factors affecting convention participation decisionmaking. Tourism Management. 2007;28:1123-1127.

8. Severt D, Wang Y, Chen P, Breiter D. Examining the motivation, perceived performance and behavioral intentions of convention attendees: Evidence from a regional conference. Tourism Management. 2007;28:399-408.

9. Jelena D, Vanja D, Daniela A, Milana P, Uglješa S. Conference Attendees' Satisfaction: Evidence from Belgrade (Serbia). TURIZAM. 2012;16(4):170-179.

10. The Strategy of Tourism Development of the Republic of Serbia 2005-2015. Weber, K. and Chon, K. 2002. Convention tourism international research and industry perspectives, Haworth Press Inc.,U.S.

\section{Figures}




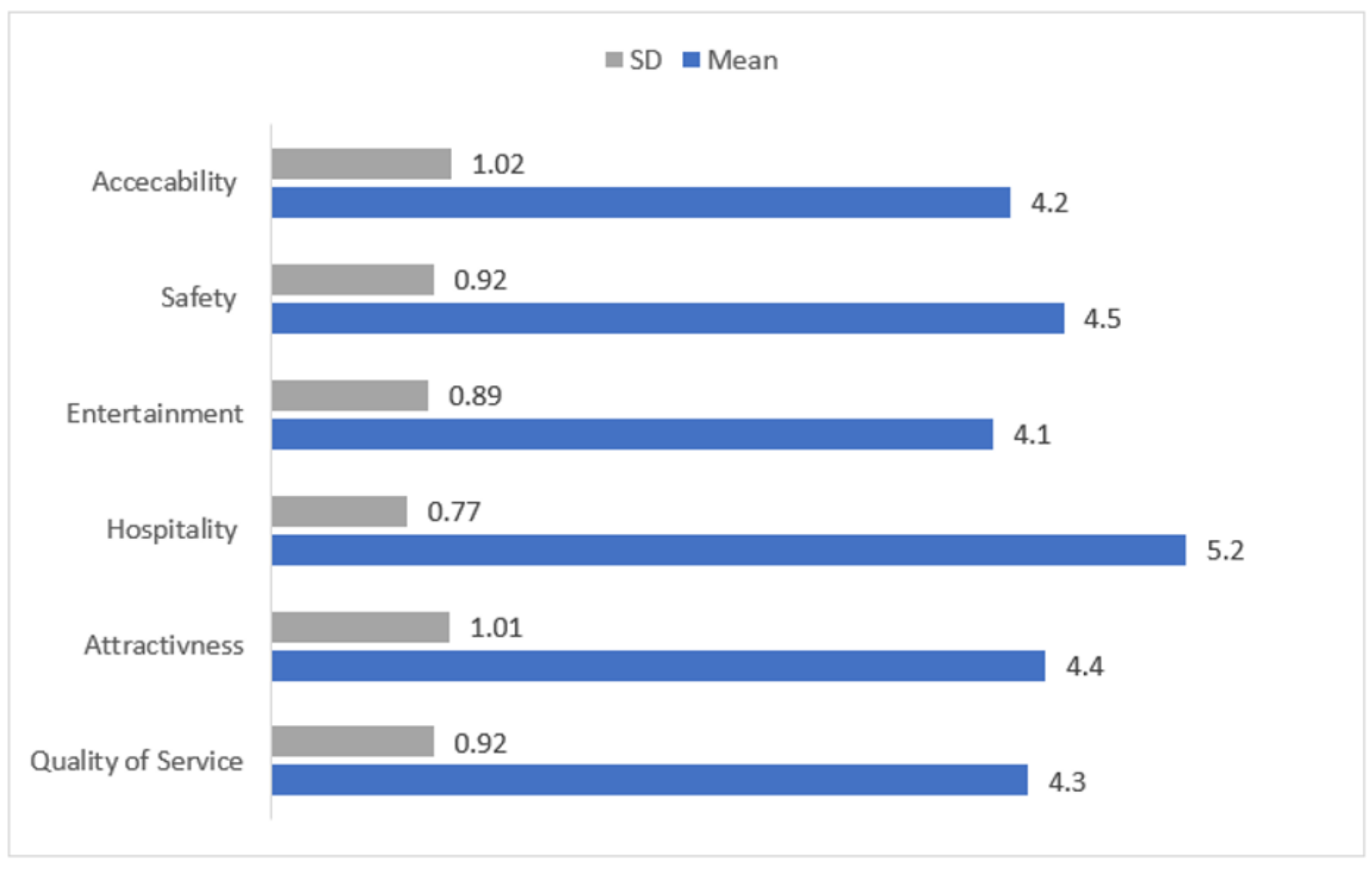

Figure 1

Mean values and standard deviation for destination attributes 


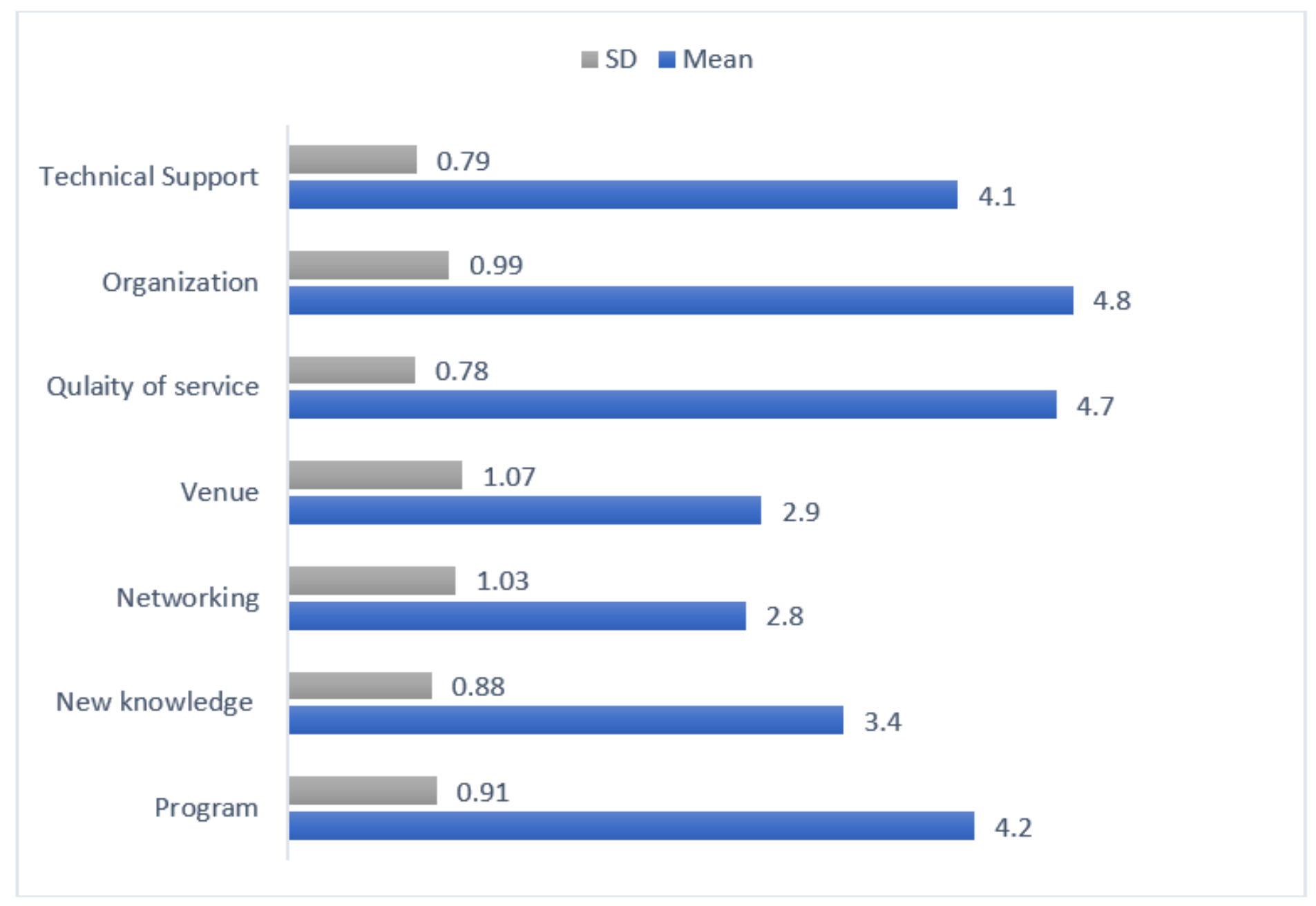

Figure 2

Mean values and standard deviation for conference attributes 